\title{
The 60th anniversary of Jean-Pierre Badiali
}

On October 20, 2001 Jean-Pierre Badiali celebrated his 60th birthday. On this occasion the Editorial board of "Condensed Matter Physics" decided to honour him with a collection of scientific papers. With great pleasure numerous researchers, colleagues and co-workers of Jean-Pierre have contributed their articles. The Editorial Board of "Condensed Matter Physics" express sincere gratitude to all of them. The highly skilled contributions are connected with surface science, electrochemistry, statistical theory of condensed matter and other fields which are close to J.P.Badiali's interest during many years of his scientific activity.

J.P.Badiali was born on October, 20, 1941 at Mirande in France. Having graduated as an engineer from Ecole Superieure d'Electricité in 1970, he entered the Centre National de la Recherche Scientifique (CNRS) as a scientist. Here he goes the scientific way from a position of "Stagiare de recherches" to Research Director of Exceptional Class. Four times was J.P.Badiali elected as a member of the National Committee of the CNRS. From 1995 to 2000 he was President of the Section "Molecule: Structure and Interactions" of the National Committee of the CNRS. Now he is a member of the Scientific Council of the CNRS and works as a head of the team "Theory of Interfaces" at the "Laboratoire d'Electrochimie et Chimie Analytique" of Ecole Nationale Superieure de Chimie de Paris and Université P. et M.Curie.

J.P.Badiali is the author of over 130 papers published in international journals including the four chapters in collective books. In 1986 he was awarded the Silver medal of the CNRS.

J.P.Badiali grants significant attention to the Ukrainian-French scientific collaboration. The permanent and fruitful collaboration of J.P.Badiali with the Institute of Condensed Matter of the National Academy of Sciences of Ukraine has been going on since 1991. J.P.Badiali is a genuine scientist: devotion to science is a specific feature of his life. Jean-Pierre kindly agreed to write some short notes about his scientific life which we gladly publish in this issue.

Due to the limit of the journal space it was impossible to include herein all the received articles devoted to J.P.Badiali. Another part of the papers will be published in 2002 (vol. 5, No. 2).

The Editorial Board of "Condensed Matter Physics" congratulates our good friend and member of the Editorial Board on the occasion of his anniversary and acknowledges his unique and valuable contribution to science. 
